\title{
Enoturismo e Turismo de Experiência: novas possibilidades para a inclusão de pessoas com deficiência visual - Vinícola Dezem (Toledo, Paraná, Brasil)
}

\section{Wine Tourism and Experience Tourism: new possibilities for inclusion of visual impairment people - Dezem Winery (Toledo, Paraná, Brazil).}

\author{
Camila Bizinelli (BIZINELLI, C.) ${ }^{*}$, \\ Franciele Manosso (MANOSSO, F.) ${ }^{* *}$, \\ Maria Henriqueta Sperandio Gimenes-Minasse (GIMENES-MINASSE, M. H. S.) ${ }^{* * *}$ e \\ Silvana do Rocio de Souza (SOUZA, S. do R. de ) ${ }^{* * * * *}$
}

RESUMO - O enoturismo é um segmento em amplo crescimento, no Brasil e no exterior. Este artigo tem como objetivo averiguar como o enoturismo e o turismo de experiência podem ser trabalhados juntos como forma de inclusão de pessoas com deficiência, sobretudo a visual. Para alcançar este objetivo foi realizada uma pesquisa bibliográfica e documental, bem como um estudo de caso da Vinícola Dezem (Toledo, Paraná), envolvendo não apenas a visita ao local, mas, também a realização de um conjunto de entrevistas (com representantes da vinícola e com deficientes visuais). Como principais resultados destacaram-se: o empreendimento em questão ainda não se encontrava pronto para receber pessoas com deficiência visual e os principais impeditivos se referem às barreiras visuais e ao atendimento prestado. Em relação às necessidades das pessoas com deficiência visual, a maioria diz respeito a barreiras estruturais e comunicacionais - incluindo sinalização, textos em braile e atendimento. Observou-se que as principais adaptações necessárias podem ser realizadas sem que haja grandes investimentos financeiros.

Palavras-Chave: Enoturismo; Turismo de Experiência; Deficiência Visual; Acessibilidade; Vinícola Dezem; Toledo - PR.

\footnotetext{
* Graduação em Turismo (Bacharelado) e Mestranda em Geografia pela Universidade Federal do Paraná (UFPR). Bolsista da Coordenação de Aperfeiçoamento de Pessoal de Nível Superior (CAPES). Endereço físico para correspondência: Rua Maria Bizinelli, 470. CEP: 81210-154 - Curitiba (Paraná) - Brasil. Telefone para contato: (41) 9624-8874.E-mail: ca_bizinelli@ hotmail.com

** Graduação em Turismo (Bacharelado) e Mestranda em Geografia pela Universidade Federal do Paraná (UFPR). Bolsista da Coordenação de Aperfeiçoamento de Pessoal de Nível Superior (CAPES). Endereço físico para correspondência: Rua Santa Rita, 542 (Cidade Jardim). CEP: 83035-250 - São José dos Pinhais (Paraná) - Brasil. Telefone para contato: (41) 9937-0655. E-mail: fran-manosso@ hotmail.com

*** Graduação em Turismo (Bacharelado), Especialização em Planejamento e Gestão do Turismo, Mestrado em Sociologia e Doutorado em História pela Universidade Federal do Paraná (UFPR). Professora e Pesquisadora do Departamento de Geografia, Turismo e Humanidades e do Mestrado em Sustentabilidade na Gestão Ambiental da Universidade Federal de São Carlos (UFSCAR). Endereço físico para correspondência: Rua Dr. Fausto Ferraz, 227 (Bela Vista). CEP 01333-030 - São Paulo - SP (Brasil). Telefone para contato (11) 99739-8757. Email: mariegimenes@gmail.com

**** Graduação em Turismo (Bacharelado) e Especialização em Planejamento e Gestão do Turismo pela Universidade Federal do Paraná (UFPR), Mestrado em Educação pela Universidade Tuiuti do Paraná e Doutorado em Geografia (UFPR). Professora e Pesquisadora do Departamento de Turismo da Universidade Federal do Paraná. Endereço físico para correspondência: Rua Doutor Faivre, $405-3^{\circ}$ andar (Centro). CEP: 80060-140 - Curitiba - PR (Brasil). Telefone para contato: (41) 3360-5109. Email: silvanarcsouza@hotmail.com
} 
ABSTRACT - The wine tourism is a high-growth segment in Brazil and overseas. This article aims to investigate how the wine tourism and experience tourism could be worked together as a way of including people with disabilities, particularly visual impairment. To achieve this goal a bibliographic and documentary research was carried out, as well as a case study in the Dezem Winery (Toledo, Paraná), involving not only the site visit, but also the realization of a set of interviews (with winery representatives and with visual impairment people). As the main results: the company visited was not ready to receive people with visual disabilities and the major impediments are related to visual barriers and the service provided. In relation to the needs of people with visual impairments, the majority are related to structural and communication barriers including signaling, braille texts and attendance. It was observed that the main adaptations could be performed without any major investments.

Key Words: Wine Tourism; Experience Tourism; Visual Impairment; Accessibility; Dezem Winery; Toledo - PR. 


\section{INTRODUÇÃO}

O enoturismo é um segmento da atividade turística onde o deslocamento de pessoas é motivado, principalmente, por atividades relacionadas à produção e degustação de vinhos, bem como à vivência das tradições, da cultura, da gastronomia, entre outros elementos presentes nas localidades vitivinicultoras (VALDUGA, 2007). Nesse sentido, o enoturismo tem a possibilidade de envolver o visitante em uma atmosfera geradora de experiências únicas, pois o aroma da uva e o sabor do vinho são tão específicos do terroir $^{1}$ quanto o modo de falar e o estilo de viver que são próprios de determinada região (TONINI, 2009). Do ponto de vista do enoturismo experiencial, um importante exemplo é o Tour da Experiência (desenvolvido na Região da Uva e do Vinho, no Rio Grande do Sul) que tem como objetivo encantar, emocionar e transformar a sensibilidade dos turistas, marcar suas almas proporcionando experiências inesquecíveis (MINISTÉRIO DO TURISMO, 2013).

Este artigo, então, tem como objetivo central averiguar como o enoturismo e o turismo de experiência podem ser trabalhados juntos, como meio de inclusão de pessoas com deficiência, sobretudo a visual. Nesse sentido, verifica-se a importância de estudos que contemplem as questões do enoturismo e da experiência para a inclusão de pessoas com deficiência visual, propondo soluções e atividades, tendo em vista o crescimento deste segmento no Brasil e a precariedade observada em termos de acessibilidade de muitos equipamentos e destinos turísticos. Há um grande potencial a ser descoberto pelo público demandante e pelos próprios gestores.

A escolha de pessoas com deficiência visual como 'protagonistas' deste estudo deu-se, especialmente, em virtude de ser um público carente no que se refere à oferta turística. Isto, principalmente, devido ao fato de boa parte das atividades relacionadas ao turismo estarem ligadas à contemplação (paisagens, monumentos, patrimônio edificado etc.) ou à ação (atividades radicais, de aventura, ecoturismo, esportes etc.), situações em

\footnotetext{
${ }^{1} \mathrm{O}$ termo terroir veio a ganhar conotação positiva nos últimos 60 anos, quando a valorização da delimitação dos vinhedos nas denominações de origem de vinhos na França veio a balizar critérios associados à qualidade de um vinho, incluindo o solo e a variedade, dentre outros. A palavra terroir passa a exprimir a interação entre o meio natural e os fatores humanos. E esse é um dos aspectos essenciais do terroir, de não abranger somente aspectos do meio natural (clima, solo, relevo), mas também, de forma simultânea, os fatores humanos da produção - incluindo a escolha das variedades, aspectos agronômicos e aspectos de elaboração dos produtos (TONIETTO, 2007).
} 
que se não houver um extremado preparo para desenvolvimento de atividades para a pessoa com deficiência visual, estas se tornam impraticáveis.

Nesse sentido, foi realizado um estudo sobre a Vinícola Dezem (Toledo, Paraná), escolhida por ser apresentada como o único destino enoturístico paranaense, no site Enoturismo Brasil (2011). Durante a coleta de dados, conduzida no final do ano de 2011 e início de 2012, realizou-se uma entrevista semiestruturada com o responsável pelo empreendimento, procurando identificar sua visão sobre o desenvolvimento do enoturismo na propriedade e as adaptações realizadas para receber pessoas com deficiência, juntamente com a entrevista os pesquisadores empregaram a técnica da observação participante, analisando, efetivamente, se o empreendimento enoturístico encontrava-se em conformidade com as normas de acessibilidade propostas pela ABNT - Associação Brasileira de Normas Técnicas. Ainda, foram entrevistadas (com utilização de um roteiro de entrevistas) doze pessoas com deficiência visual para conhecer as dificuldades enfrentadas por elas ao realizar atividades turísticas. Foram também realizadas pesquisas bibliográficas e documentais, objetivando obter uma visão mais ampla dos conceitos de enoturismo e de turismo de experiência, bem como compreender os vieses presentes no cotidiano das pessoas com deficiência visual. Os resultados obtidos são apresentados na sequência.

\section{ENOTURISMO, UMA BREVE INTRODUÇÃO}

O vinho como interesse de viagem existe há centenas de anos, e muitos dos chamados Gran Tours já incluíam em suas programações educacionais visitas a vinhedos e vinícolas (HALL et al, 2004). Porém, foi no século XIX que o vinho tornouse um interesse específico de viagem e, mais recentemente, a união entre vinho e a vitivinicultura foi reconhecida por produtores e pelo próprio trade turístico como uma importante oportunidade de desenvolvimento (HALL et al, 2004). Esta importância é tamanha que, segundo Cambourne e Macionis (2004), o enoturismo já era reconhecido desde o final da década de 1990 como o buzzword ${ }^{2}$ que substituirá o ecoturismo como o mais inovador segmento do mercado turístico nos próximos anos.

\footnotetext{
${ }^{2}$ Palavra ou termo em voga, da moda.
} 
Assim, o enoturismo, é caracterizado por Hall e Macionis (1998) pela visitação aos vinhedos, cantinas, festivais vinícolas e exposição de vinhos, sendo usufruído por aqueles cujo interesse pelo vinho e pela uva e/ou conhecer as características de uma região vitivinícola são os principais fatores motivacionais. Nesse sentido, o vinho é observado como um atrativo motivacional dentro da atividade turística, à medida que dentro da indústria vinícola ele é trabalhado como uma maneira de se construir relações com os clientes que podem experimentar e conhecer os produtos nas diferentes fases de produção.

Beames (2003) salienta que o enoturismo está intrinsecamente relacionado a toda experiência que o enoturista vivencia, quando este se encontra cercado pelo vinho e pela gastronomia de um local. Costa (2009) destaca que o enoturismo surgiu como um 'subsegmento' do turismo gastronômico, para acolher uma demanda de pessoas que contemplam um bom vinho ou, mesmo para que os enólogos, na busca pelo aperfeiçoamento, tivessem opções de roteiros mais elaborados, nos quais pudessem analisar determinado vinho, desde a produção da uva, até a harmonização do mesmo com pratos típicos da gastronomia local.

De acordo com Valduga (2012, p. 130) pode-se caracterizar o enoturismo como:

Um segmento do fenômeno turístico, que pressupõe deslocamento de pessoas, motivadas pelas propriedades organolépticas e por todo o contexto da degustação e elaboração de vinhos, bem como a apreciação das tradições, de cultura, gastronomia, das paisagens e tipicidades das regiões produtoras. É um fenômeno dotado de subjetividade, em que a principal substância é o encontro com quem produz uvas e vinhos.

Nesta conjuntura, cabe enfatizar que no Brasil a uva e o vinho tornaram-se atração turística no sul do país na década de 1930, principalmente a partir de eventos que foram organizados com a finalidade de promover e divulgar o universo do vinho (ZANINI, 2007). A partir desse momento, o desenvolvimento do enoturismo foi bastante próspero, e atualmente há mais de 100 vinícolas em todo o país que recebem visitantes; algumas delas caracterizam-se como verdadeiros complexos agroturísticos, contando com pousadas e restaurantes, oferecendo cursos específicos e degustações (ENOTURISMO BRASIL, 2011).

O incremento na demanda se deve, também, ao aumento do consumo de vinhos no país - segundo a União Brasileira de Vitivinicultura (UVIBRA, 2013), este aumentou 
aproximadamente $32 \%$ nos últimos cinco anos. A produção vinícola brasileira também vem aumentando gradativamente e segundo o Instituto Brasileiro do Vinho - Ibravin (2013), a produção de uvas é da ordem de 1,2 milhões de toneladas/ano, sendo que $45 \%$ deste total destinam-se à elaboração de vinhos. Ainda em relação ao consumo de vinhos no país, o International Wine and Spirit Research (ISWR, 2011) realizou uma pesquisa em 2006 e fez uma previsão de consumo de 369 milhões de litros para 2011, face aos 326 milhões de litros consumidos naquele ano. Assim, eclode um novo cenário, com consumidores mais exigentes que buscam conhecer questões relativas à qualidade, procedência e diversidade do vinho, tornando o mercado vitivinicultor mais competitivo para os vinhos produzidos pelas vinícolas brasileiras (TONIETTO, 2003).

No que se refere ao perfil do enoturista, é preciso destacar a carência de estudos existentes. Há alguns estudos que abordam o perfil demográfico (relativo ao sexo, à idade, à renda e à origem), e psicográfico (motivações, estilos de vida, interesses, atitudes e valores) dos enoturistas (BIZINELLI, 2011). Sobre o perfil demográfico, segundo o que apresentam Mitchell et al (2004), em pesquisa realizada na Austrália, há algumas questões que se destacam, sendo as quais: a faixa etária dos enoturistas que concentra-se entre 30 e 50 anos, sua renda é relativamente alta e são originários do entorno dos locais/vinícolas visitados. No que tange ao perfil psicográfico dos enoturistas, os mesmos autores destacam, prioritariamente, o estilo de vida e as motivações dos mesmos. Sobre o estilo de vida, afirmam que os enoturistas são consumidores regulares de vinho, têm um conhecimento entre o nível intermediário e o avançado do assunto e frequentam vinícolas e regiões vitivinicultoras várias vezes durante o ano.

No que diz respeito às motivações do turista em praticar o enoturismo, estudos de Tach (2007) e Gimenes, Bizinelli e Manosso (2012) indicam: desejo de degustar o vinho; aprender sobre o cultivo da vinha e do processo de fabricação do vinho; conhecer o universo do vinho (os parreirais, a vinícola, o produtor); desfrutar do universo rural; harmonizar o alimento com o vinho; divertir-se; desfrutar da aura de romance, sofisticação e bucolismo associados à cultura da uva e do vinho; apreciar a arquitetura e a arte dos espaços de produção e de degustação das vinícolas; aprender sobre as questões ambientes; desfrutar dos benefícios gerados pelo vinho à saúde. 
Outro estudo que merece menção é o de Serrenho e Águas (2006), que adaptaram a classificação apresentada por Hall e Macionis (1998) e Charters e AliKnight (2002), discutindo as questões que devem ser consideradas quando se vislumbra o 'retrato' do consumidor denominado enoturista. Serrenho e Águas (2006) apresentam a seguinte classificação: Wine Lovers (visitantes com interesse e conhecimento elevados); Wine Interested (visitantes com interesse elevado e conhecimento reduzido) e Wine Curious/Hanger (visitantes com interesse e conhecimentos reduzidos).

O enoturismo, ainda, pode ser caracterizando como um sistema centrado na experiência enoturística que, de certa maneira, influencia e é influenciado pelos aspectos individuais do visitante e da oferta como um todo. Desse modo, a demanda enoturística pode ser considerada distinta quando se estuda o visitante individualmente, devido aos seus aspectos culturais e sua percepção, sendo a última considerada uma união entre experiência passada, informações e preferências. Ambas, quando combinadas com motivações específicas, criam uma expectativa, bem como, uma imagem da destinação enoturística (TONINI, 2007).

Nesta conjuntura, cabe abordar as questões relacionadas à experiência turística, seus conceitos e vieses, procurando uma visão mais abrangente de como a experiência pode-se aliar ao enoturismo, a fim de 'criar' alternativas de lazer para pessoas com deficiência visual.

\section{TURISMO DE EXPERIÊNCIA: CONCEITOS E CARACTERÍSTICAS}

Pine e Gilmore (1999) discutiram em sua obra o conceito de Economia da Experiência a partir da percepção de que uma vivência memoravelmente única e intransferível pode ser analisada a partir da perspectiva experiencial. Neste contexto, pode-se salientar o que Bordás (2003) trata, ao afirmar que os conceitos de singularidade, conexão, crescimento pessoal e contribuição para um mundo melhor são vieses importantes dentro da experiência, pois a demanda atual busca, cada vez mais, consumir de modo mais emocional, ou seja, quer que seu coração (e não sua razão) seja conquistado pelas experiências ofertadas por determinado empreendimento ou localidade. 
Nesse sentido, Saraiva (2009) destaca que o turismo de experiência tem como questão primordial fazer com que o cliente interaja mais com o destino escolhido, para que desse modo, possa vivenciar o cotidiano das cidades visitadas, bem como o lazer e a culinária local. Assim, o turismo de experiência não deve ser trabalhado dentro dos moldes do turismo de massa e, sim, através da exclusividade e personalização de seus produtos e serviços.

Logo, para os empreendimentos vitivinicultores que trabalham ou desejam trabalhar com o enoturismo, a incorporação de estratégias que criem uma experiência diferenciada para os visitantes é primordial. Pine II e Gilmore (1999) e Schmitt (1999) entendem experiência como o resultado do encontro entre o cliente e o empreendimento, onde o consumidor deve se submeter ou viver situações que resultem na criação de experiências e emoções podendo-se ter vivências memoráveis agregando um valor muito maior ao consumo de determinado produto ou serviço.

Uma experiência memorável é criada, segundo Pine II e Gilmore (1999) quando são contemplados elementos de aprendizagem (o desejo de sair da experiência tendo aprendido algo), de entretenimento (não apenas o divertimento, mas a criação de lembranças a partir das experiências vivenciadas), da estética (capacidade de encantar visualmente) e da evasão (capacidade de envolver o consumidor por meio da emoção e dos sentidos).

De acordo com Schmitt (1999) os consumidores querem adquirir em suas compras, assim como em suas viagens, mais que apenas atributos: os mesmos querem ser entretidos, estimulados tanto mentalmente quanto emocionalmente, para que desse modo suas experiências tornem-se memoráveis. Portanto, segundo Gilmore e Pine II (2002), os clientes conseguem vivenciar uma experiência considerada inesquecível quando o empreendimento emprega, de maneira intencional, serviços como uma 'cena' e os bens como um 'adereço', para que assim o que for experenciado seja único quando comparado a outras vivências que o mesmo teve em diferentes localidades e empreendimentos. Nesta conjuntura, Gândara, Gimenes e Mascarenhas (2009, p. 187) destacam que:

O turista contemporâneo deseja deslocar-se para destinos onde possa mais que visitar e contemplar, mas também viver, emocionar-se, ser o personagem da sua própria viagem. Ele anseia envolver-se nas experiências físicas e/ou mentais, gerando uma demanda por produtos específicos e mais complexos, 
capazes de propiciar tal satisfação. Esse aumento dos padrões de exigência se dá, também, por conta do aumento do acesso de informações e da familiaridade do próprio turista com outros destinos turísticos, o que lhe permite fazer comparações entre suas próprias experiências turísticas.

Os pesquisadores que discutem o comportamento do consumidor começaram a reconhecer, a partir da década de 1980, a perspectiva experiencial do consumo do enoturista, isto é, relatam a importância da natureza hedonista dos diferentes bens e serviços, concedendo destaque ao enoturismo e seus consumidores, pois o segmento tem em sua base os aspectos ligados às questões do hedonismo. O hedonismo, segundo Flocker (2007), pode ser compreendido como uma doutrina que considera o prazer ou a felicidade como o único, e até mesmo o principal bem da vida, constituindo um estilo de vida de iluminação e gozo. Nessa perspectiva, segundo Hall et al (2004), a experiência enoturística é balizada pelas preferências pessoais de cada indivíduo, tanto pelo que é ofertado de fato quanto por aquilo que é experenciado durante o consumo. Por conseguinte, o enoturista utilizar-se-á de experiências vivenciadas previamente, informações obtidas (internet, amigos, publicações impressas, entre outros) e seu imaginário, para a criação de expectativas e idealizações, as quais ele buscará satisfazer durante a viagem realizada. Desta forma, vivenciar uma experiência satisfatória não depende somente de uma oferta adequada, mas de uma compreensão profunda da demanda que, como citado anteriormente, de algumas décadas pra cá os turistas têm buscado uma diferenciação nos serviços, que provém da busca pelo prazer e pela felicidade (HALL et al, 2004).

Devido à personalização e imersão nos produtos as experiências acabam afetando e transformando os turistas. O turismo deixa então de ser observado como uma atividade de simples contemplação, para ser percebido como um componente que propicia a integração do turista em culturas diversas, oferecendo-lhes novas e memoráveis experiências. E é neste sentido, de fornecimento de oportunidades para novas experiências memoráveis, que se sugere o emprego do enoturismo aliado à experiência, visando à inclusão de pessoas com deficiência visual na atividade. 


\section{PESSOAS COM DEFICIÊNCIA VISUAL: NECESSIDADES E DEMANDAS}

Segundo Sá et al (2007), a visão é o sentido que impera na hierarquia entre os demais e ocupa uma posição proeminente no que se refere à percepção e integração de formas, contornos, tamanhos, cores e imagens que estruturam a composição de uma paisagem ou de um ambiente. Torna-se desta maneira o elo que integra os outros sentidos, além de permitir a associação entre som e imagem, imitação de um gesto ou comportamento e exercício de atividades exploratórias inseridas em espaços delimitados.

Nesta perspectiva, Bizinelli (2011) salienta que a visão é então um dos sentidos que auxilia na compreensão do mundo, ao mesmo tempo em que pode proporcionar a atribuição de significados para objetos, conceitos e ideias. E em sua ausência, discernir as coisas se torna uma tarefa muito mais complexa e pode ser responsável por causar situações de embaraço, já que a realidade espacial, por exemplo, fica afetada; e o reconhecimento de valor visual e estético dos objetos, cores e outras características que não podem ser apreendidas pelos demais sentidos humanos torna-se, também, muito mais restrito.

Observando-se a importância do sentido da visão para o cotidiano das pessoas, cabe destacar os tipos de deficiências visuais existentes, sendo eles a cegueira e a baixa visão. Logo, Sá et al (2007, p. 15) afirmam que:

\footnotetext{
A cegueira é uma alteração grave ou total de uma ou mais das funções elementares da visão que afeta de modo irremediável a capacidade de perceber cor, tamanho, distância, forma, posição ou movimento em um campo mais ou menos abrangente. Pode ocorrer desde o nascimento (cegueira congênita), ou posteriormente (cegueira adventícia, usualmente conhecida como adquirida) em decorrência de causas orgânicas ou acidentais.
}

Complementando esta definição, tem-se o que apresenta Martins (2008, p. 18) cegueira é a ausência de visão que engloba uma acuidade visual ("a capacidade de discriminação de formas") inferior a 0,05 ou um campo visual (amplitude e abrangência do ângulo da visão em que os objetos são focalizados) inferior a $10^{\circ}$. Já a baixa visão (ambliopia, visão subnormal ou visão residual), tem em sua definição uma maior complexidade devido à variedade e à intensidade de comprometimentos das funções visuais (que englobam desde a simples percepção de luz, até a redução da acuidade e do 
campo visual que interferem ou limitam a execução de tarefas e o desempenho geral de qualquer ser humano) (SÁ et al, 2007).

Sobre deficiência visual, Martins (2008, p. 17) destaca que:

\begin{abstract}
A forma como as pessoas com deficiência visual utilizam os sentidos para percepcionar o mundo exterior é a principal diferença que as distingue das pessoas normo-visuais. Uma vez que a percepção visual não lhes é acessível, estamos a falar de uma experiência sensorial do mundo qualitativamente diferente, não de ordem quantitativa, dado que as pessoas deficientes visuais organizam de forma própria os quatro sentidos que dispõem, tirando o maior partido deles, de modo a obterem uma informação bastante precisa do mundo que as rodeia. [...] A qualidade de informação que adquirem através destes sentidos é sem dúvida mais relevante em relação à da pessoa normovisual, acostumada a percepcionar o mundo exterior através do sentido da visão sem utilizar e potenciar as restantes fontes de informação também elas complementares à percepção.
\end{abstract}

Nesta conjuntura, é imprescindível criar condições adequadas de estímulo e acessibilidade, respeitando a todos e objetivando a inclusão das pessoas com deficiência, não só na atividade turística, mas em todo âmbito social. Kushano e Almeida (2008) defendem que a falta ou a redução de um dos sentidos não pode ser observada como o principal obstáculo para a inclusão dos portadores de deficiência como cidadãos plenos de direitos e deveres. Cabe, neste contexto, destacar o termo 'acessibilidade', que segundo Melo (2006) tem sido encarado como um sinônimo do compromisso de melhorar a qualidade de vida de pessoas com deficiência (perceptual, cognitiva, motora e múltipla), uma vez que estas pessoas, comumente, sofrem influência direta da existência das chamadas barreiras nos vários ambientes, produtos e serviços que utilizam. A acessibilidade não deve estar ao alcance somente nos espaços físicos, mas também à informação, aos instrumentos de trabalho e estudo, aos produtos e serviços, dizendo respeito à qualidade de vida de todas as pessoas.

É importante ressaltar, nessa discussão, a existência de uma legislação específica sobre o tema, que tem como objetivo ofertar condições adequadas para os usos do espaço urbano, dos serviços e dos sistemas pertinentes à comunicação, transporte, entre outros. No Brasil, os parâmetros de implantação da acessibilidade são definidos pela Associação Brasileira de Normas e Técnicas (ABNT), sendo que as normas que merecem ser salientadas são: 
a) NBR 9050:2004 - Acessibilidade a edificações, mobiliário, espaços e equipamentos urbanos;

b) NBR 14022:1998 - Acessibilidade à pessoa com deficiência em ônibus e trólebus, para atendimento urbano e intermunicipal;

c) NBR 14273:1999 - Acessibilidade da pessoa com deficiência no transporte aéreo comercial;

d) NBR 13994:2000 - Elevadores de passageiros - elevadores para transporte de pessoa com deficiência;

e) NBR 15320:2005 - Acessibilidade à pessoa com deficiência no transporte rodoviário;

f) NBR 14021:2005 - Transporte - Acessibilidade no sistema de trem urbano e metropolitano;

g) NBR 15250:2005 - Acessibilidade em caixa de autoatendimento bancário;

h) NBR 15290:2005 - Acessibilidade em comunicação na televisão (MTUR, 2009, p. 13).

Muito do conteúdo legislado diz respeito às barreiras enfrentadas e as formas de eliminá-las ou minimizá-las. Pagliuca et al (2007, p. 581) discorrem sobre as barreiras que as pessoas com deficiência podem enfrentar, destacando que:

A conquista por espaços livres de barreiras arquitetônicas implica a possibilidade e a condição de alcance para que portadores de deficiência utilizem com segurança e autonomia as edificações, mobiliários, os equipamentos urbanos, os transportes e meios de comunicação.

De acordo com o Manual de Turismo e Acessibilidade (2009) as categorias de barreiras são as seguintes:

- Barreiras urbanísticas: as existentes nas vias públicas e nos espaços de uso público;

- Barreiras nas edificações: as existentes no entorno e interior das edificações de uso público e coletivo e nas áreas internas de uso comum nas edificações de uso privado multifamiliar;

- Barreiras nos transportes: as existentes nos serviços de transportes que impedem ou dificultam o ingresso ao interior dos veículos de transporte público, privado, aos terminais, às estações e aos pontos de parada;

- Barreiras nas comunicações e informações: qualquer entrave ou obstáculo que dificulte ou impossibilite a expressão ou o recebimento de mensagens por intermédio dos dispositivos, meios ou sistemas de comunicação, sejam ou não de massa, bem como aqueles que dificultem ou impossibilitem o acesso à informação.

No caso das pessoas com problemas/ausência de visão é importante observar que todas elas são impactantes. No entanto, as barreiras de comunicação e informação 
terminam se destacando, justamente pela dificuldade de receber mensagens por intermédio de diferentes sistemas, materiais e dispositivos, que em geral, tem algum apelo visual. Torna-se imprescindível, então, realizar adequações nestes sistemas, dispositivos e materiais, para que a pessoa com deficiência visual consiga ter pleno acesso e entendimento das informações necessárias e desejadas (BIZINELLI, 2011).

Kaufman (1995) e Hoggs e Wilson (2004) citam que são inúmeros os obstáculos enfrentados pelo portador de deficiência que deseja exercer seu papel como consumidor, pois as dificuldades começam a partir dos aspectos básicos, tais como: a falta de educação especializada, de pessoas preparadas para bem receber e tratar adequadamente pessoas com deficiência em situações de consumo. Assim, Sassaki (2003) salienta que as barreiras mais comuns encontradas por pessoas com deficiência nos locais destinados ao lazer e ao turismo são: atitudinais, comunicacionais e arquitetônicas, sendo que as duas primeiras relacionam-se, diretamente com a falta de preparo dos funcionários para atender as pessoas com deficiência.

Faria e Motta (2012) realizaram uma pesquisa que permitiu identificar sete fatores considerados restritivos para o consumo de serviços turísticos por pessoas com deficiência visual, sendo eles: tempo, recursos financeiros, questões pessoais, importância da companhia, barreiras atitudinais, barreiras arquitetônicas e atendimento, sendo que os fatores que mais se destacaram são aqueles relacionados ao atendimento e à importância da companhia.

Neste âmbito, Silva e Boia (2003) e Darcy (2009) indicam algumas barreiras que as pessoas com deficiência enfrentam ao consumir um serviço turístico, tais como: a falta de preparo dos prestadores de serviços, barreiras arquitetônicas, poder aquisitivo insuficiente para arcar com os custos extras recorrentes das necessidades especiais e desinteresse tanto da população quanto do governo no que tange à inclusão das pessoas com deficiência.

Cabe destacar ainda que diversos estudos acadêmicos apontam que as atividades relacionadas ao lazer turístico podem ser consideradas uma oportunidade relevante para a inclusão social de pessoas com deficiência (ALMEIDA, 2006). Todavia, Baker, Stephens e Hill (2002) reconhecem que a verdadeira inclusão das pessoas com deficiência dentro da sociedade, sobretudo como consumidores, só ocorrerá quando estes indivíduos forem ouvidos, de modo a manifestar quais adaptações podem e 
precisam ser feitas para que sua experiência de consumo seja satisfatória, tanto na atividade turística quanto em qualquer outra atividade a ser realizada.

\section{METODOLOGIA}

Para se atingir o objetivo central do artigo de averiguar se o enoturismo e o turismo de experiência poderiam ser trabalhados juntos, como meio de inclusão de pessoas com deficiência, sobretudo a visual, fez-se necessário o emprego de alguns procedimentos metodológicos, sendo estes destacados no presente tópico. Primeiramente, cabe salientar que o estudo se caracteriza, prioritariamente, como uma pesquisa de natureza aplicada, pois a mesma tem como desígnio a geração de conhecimentos passíveis de aplicação prática, cabendo destacar que esse tipo de pesquisa faz alusão ao procedimento investigativo de novos conhecimentos, indispensáveis para determinar os meios pelos quais se pode ampliar e aprimorar os processos ou sistemas, com vistas ao contentamento de uma necessidade específica e reconhecida (DENCKER, 1998).

Logo, o estudo em questão pode ser definido como de caráter exploratório. Popper (1974) discorre que tal categorização tem como principal finalidade desenvolver, esclarecer e, ainda modificar conceitos e ideias, com o intuito de formular hipóteses pesquisáveis para estudos futuros, é o tipo de pesquisa que apresenta menor rigidez no planejamento, sendo necessário que seja feito um levantamento bibliográfico, bem como entrevistas.

A pesquisa bibliográfica, segundo Popper (1974), pode ser definida como uma síntese referente ao tema a ser pesquisado. Dessa forma, pode-se dizer que a pesquisa bibliográfica visa conhecer e analisar as contribuições culturais e científicas do passado sobre determinado assunto, tema ou problema (CERVO; BERVIAN, 1983). Outra técnica empregada neste estudo foi a pesquisa documental, realizada a partir de materiais que não receberam tratamento analítico (DENCKER, 1998). Ambas as técnicas foram utilizadas para discutir temas como o enoturismo, o turismo de experiência e as pessoas com deficiência visual, para que desse modo, os resultados de pesquisa pudessem ser analisados de maneira mais abrangente. 
A partir do que foi pesquisado para a formatação dos roteiros de entrevistas, bem como, para a elaboração do marco teórico, buscou-se elencar alguns pontos a serem observados durante a coleta de dados, realizada no final do ano de 2011, na Vinícola Dezem (Toledo - Paraná). Assim, cabe destacar o emprego da técnica de observação direta, que é conceituada por Barbosa (1998) como um método que depende mais das habilidades do pesquisador em captar as informações, julgá-las sem interferências e registrá-las com fidelidade, sendo aplicada com o pesquisador encontrando-se fora das situações e fatos que estão sendo observados.

Por fim, cabe destacar a realização de entrevistas tanto com as pessoas com deficiência visual quanto com o responsável pela Vinícola Dezem, buscando não apenas opiniões pessoais mas também informações pertinentes, que não constam em registros escritos. Foi realizada entrevista semiestruturada, descrita por Dencker (1998) como aquela composta por perguntas balizadoras, mas que permite flexibilidade de mudanças ao longo da entrevista, dando assim maior liberdade ao pesquisador.

$\mathrm{O}$ roteiro de entrevista aplicado às pessoas com deficiência visual foi dividido em três 'blocos': o primeiro, buscando a identificação do entrevistado; o segundo, procurando caracterizar a deficiência visual do entrevistado (cegueira, baixa visão; de nascença, adquirida); o terceiro abordando especificamente o turismo e os tipos de atividades que são praticadas a lazer, bem como a disponibilidade dos entrevistados em participar de algum projeto envolvendo o enoturismo e quais fatores consideravam importantes para visitação de pessoas com deficiência visual em vinhedos/vinícolas. A entrevista previa, ainda, que o entrevistado apresentasse sugestões, propostas e considerações visando a aprimorar iniciativas voltadas para o turismo de experiência associado ao enoturismo. Em uma amostragem não quantitativa e de caráter intencional, foram entrevistadas ao todo 12 pessoas.

O roteiro de entrevista destinado ao representante da Vinícola Dezem foi estruturado em três 'blocos': o primeiro destinado à caracterização do estabelecimento (ano de fundação, funcionários, tipos de vinhos produzidos, por exemplo); o segundo destinado à caracterização do uso turístico do empreendimento (quando começou receber visitantes, número de visitas por ano, preços para o turista, entre outras informações); e o terceiro centrado na questão da acessibilidade (compreensão do entrevistado sobre o assunto, atividades que buscam atender ao público estudado, 
interesse para futuras ações voltadas para este público). O próximo tópico sintetiza e apresenta os dados obtidos e suas respectivas análises, separando por grupos pesquisados (representante da vinícola e deficientes visuais).

\section{ANÁLISE E DISCUSSÃO DOS RESULTADOS}

Tendo ciência do exposto anteriormente, nesta seção serão apresentados os resultados obtidos com a pesquisa, iniciando pelos dados coletados durante a entrevista com o responsável pela vinícola.

\subsection{ENTREVISTA COM O RESPONSÁVEL PELA VINÍCOLA}

O empreendimento pesquisado foi a Vinícola Dezem, localizada no município de Toledo, Paraná, a escolha desta se deu basicamente devido a apresentação da mesma como único destino enoturístico paranaense, no site Enoturismo Brasil (2011). Tal domínio virtual listava e divulgava as principais práticas ligadas à atividade, notícias, destinos, empreendimentos, histórico, dentre outras informações relevantes para o enoturismo brasileiro. $\mathrm{O}$ entrevistado foi o diretor comercial do empreendimento, que exercia o cargo há quatro anos.

A vinícola foi inaugurada em 2005, sendo a concretização de um projeto familiar, idealizado pelos proprietários do local. Contava com um quadro de 6 a 10 funcionários, sendo este número variável dependendo dos períodos de colheita/produção e envase. Em relação à comercialização dos produtos, os mesmos eram vendidos no mercado nacional, principalmente no estado do Paraná. A propriedade não exportava seus produtos para outros países.

Sobre a atividade turística, o entrevistado destacou que o empreendimento estava recebendo visitação desde sua inauguração. Não era preciso fazer reserva e não estava sendo cobrado nenhum valor, e a visitação - conduzida pelo próprio entrevistado incluía um passeio por toda a propriedade, com degustação ao final. A vinícola encontrava-se aberta de segunda a sexta-feira em horário comercial e aos sábados até meio-dia, não abrindo aos domingos, e a visitação não era limitada a nenhum horário 
em específico, podia ser realizada no horário em que o visitante fosse a propriedade, desde que dentro do horário de atendimento comercial da mesma. Em relação à comercialização da vinícola como um produto turístico, as principais iniciativas de marketing para a atração desses visitantes estavam sendo realizadas através de parcerias com hotéis, como o Bourbon de Cascavel. Ainda, segundo o entrevistado, utilizava-se como forma de comercialização o site da vinícola, onde se apresentavam os produtos produzidos e comercializados.

Em relação à acessibilidade, questionou-se o entrevistado sobre seus conhecimentos: o mesmo afirmou que tinha familiaridade com conceitos relacionados ao tema e que a existência de lugares acessíveis poderia ser uma alternativa para o mercado, para que se pudesse atender um público pouco explorado e que tinha grande potencial. Dentro do seguinte questionamento: "o que pensa a respeito da acessibilidade e sua prática?", o entrevistado respondeu que considerava a acessibilidade importante na medida em que permitia a inclusão de mais indivíduos na atividade turística e na sociedade de maneira geral.

Nesta perspectiva, o posicionamento do entrevistado se aproximou ao que é defendido por Almeida (2006) e Sassaki (2003), de que a atividade turística pode ser empregada como uma oportunidade real para a inclusão social de pessoas com deficiência. Contudo, apesar de reconhecer a importância da acessibilidade e das pessoas com deficiência para a atividade turística, o entrevistado afirmou que a frequência de pessoas com estas características no empreendimento estava sendo nula, nunca tendo ocorrido.

Desse modo, com base na entrevista, foi possível observar que o empreendimento não atendia a um público de pessoas com deficiência visual. O que, de certa forma, era corroborado com o que havia sido identificado na observação direta do local (explicitada na metodologia anteriormente), pois, quase que em sua totalidade, o local não possuía condições adequadas para atender as especificidades deste público, de acordo com o que é proposto na NBR 9050:2004, traduzindo assim a necessidade de se inserir a acessibilidade dentre o planejamento, não só deste empreendimento, mas de tantos outros, bem como, das atividades destes locais a fim de atender esta demanda em potencial. 
Em relação ao interesse em desenvolver ações futuras voltadas ao público com deficiência visual, o entrevistado respondeu que sim. Entretanto, segundo ele, tais ações dependeriam de um aumento da demanda desse público, para que se pudesse investir mais e de maneira consciente no desenvolvimento de instalações e contratações de pessoas especializadas. $\mathrm{O}$ entrevistado afirmou ainda que a propriedade havia dado início a um estudo sobre a sinalização do local e no material de divulgação do empreendimento, procurando diminuir as barreiras encontradas pelas pessoas com deficiência.

Ao que diz respeito a sugestões, propostas e à opinião em relação à pesquisa apresentada nesse artigo, o entrevistado considerou tratar-se de uma alternativa válida para a inclusão deste público, contudo, ponderou que o enoturismo era ainda um segmento muito pouco explorado e pouco conhecido para uma boa parte da população do país, diferentemente do que se notava no exterior. O entrevistado reforçou que além de existirem poucas iniciativas, as mesmas dificilmente tinham uma continuidade, devido principalmente, a falta de conhecimento dos empreendedores e de esforços e incentivos ao que se refere à acessibilidade.

\subsection{ENTREVISTAS COM PESSOAS COM DEFICIÊNCIA VISUAL}

A amostra envolvendo os deficientes visuais foi de caráter qualitativo não probabilístico. Foram entrevistadas doze pessoas, maiores de dezoito anos, de classes sociais e experiências de vida diferenciadas, buscando um cenário mais amplo quanto à opinião das mesmas sobre o tema em questão. Os depoentes foram contatados a partir de indicações do Instituto Paranaense de Cegos, em especial de sua ex-assistente social responsável, foram encontradas as doze pessoas utilizadas como respondentes da entrevista.

Os entrevistados em sua maioria encontravam-se na faixa dos 25 a 35 anos (42\%), também havendo depoentes nas faixas de 18 a 25 anos (33\%) e de 36 a 60 anos (25\%). A maioria dos entrevistados era de mulheres (58\%); a maioria possuía o Ensino Médio (58\%) (aqueles com ensino superior caracterizaram 25\%). Em relação ao exercício de uma atividade remunerada, houve equiparidade: metade dos entrevistados trabalhava e a outra metade não. Esta questão suscitou várias manifestações sobre as 
dificuldades encontradas por uma pessoa com deficiência visual, como a de um entrevistado que afirmou que "não são muitas escolas e até mesmo universidades que estão preparadas para o atendimento às pessoas com deficiência visual". Da mesma forma, a escassez de empresas que contratassem pessoas com este perfil também foi lembrada por muitos. O mesmo entrevistado ainda destacou, que ao que se refere ao trabalho, não eram muitas as empresas que se encontravam preparadas para receber em seu quadro de funcionários pessoas com deficiência visual, sendo necessária uma maior conscientização para que houvesse uma real inclusão dessas pessoas na sociedade como um todo e não só na atividade turística, foco do estudo.

Em relação à deficiência visual, verificou-se que a maioria dos entrevistados adquiriu a mesma devido a acidentes/doenças que afetaram a sua visão (67\%). Em relação à idade em que foi adquirida a deficiência visual, a faixa mais citada foi a de 11 a $19 \operatorname{anos}(41 \%)$. Já, ao que se refere à caracterização da deficiência visual $92 \%$ dos entrevistados possuíam cegueira, ou seja, não possuíam nenhum grau de visão.

Todos os entrevistados afirmaram conhecer o Sistema Braille ${ }^{3}$. Contudo, um dos entrevistados afirmou que apesar de conhecer o sistema, algumas pessoas tinham certa dificuldade em utilizá-lo, sendo necessário o uso de programas de computador que fazem uso de voz eletrônica para facilitar a leitura de documentos.

A grande maioria dos entrevistados (83\%) afirmou que realizava atividades de lazer e de turismo, dado que demonstrou a existência de uma demanda considerável. Nesse sentido, ao serem indagados sobre os fatores percebidos como mais importantes para viabilizar a prática de atividades turísticas em vinícolas, o aspecto mais citado foi o da comunicação e sinalização adequadas (59\%), que inclui a comunicação interpessoal durante atendimento dos visitantes por parte dos colaboradores das vinícolas e sinalização adequada para que a experiência seja potencializada ao máximo.

Outros itens citados foram o atendimento especializado (que neste caso, seriam colaboradores das vinícolas preparados para atender este público em questão, sabendo a diferença de trato de pessoas com deficiência visual de nascença e pessoas com a deficiência adquirida ao longo da vida; cuidado com termos e comentários que possa fazer durante a visitação; trato ao 'guiar' a pessoa com deficiência visual no espaço do

\footnotetext{
${ }^{3}$ O Braile é um sistema de escrita e leitura tátil para as pessoas cegas. Este sistema consta do arranjo de seis pontos em relevo, dispostos na vertical em duas colunas de três pontos cada. Os seis pontos formam o que se convencionou chamar "cela braile".
} 
estabelecimento seja ao passar coordenadas do local, até ao auxílio à locomoção, pois existem formas de condução mais adequadas destas pessoas; conhecimento das normas de acessibilidade, como a possibilidade de pessoas com deficiência se utilizarem de cães-guia; entre outras coisas) - sugerido pelos entrevistados, já que não constava nas opções - e as atividades específicas a pessoas com deficiência visual (8\% dos entrevistados afirmaram ser de grande importância à existência destas atividades para uma plena participação durante as visitações). Exemplos de atividades que foram mencionadas são: realizar o plantio de videiras e neste processo poder tatear a terra em que se plantam as mesmas, sentir o odor deste solo, suas características ao que se refere à textura; realizar a colheita das uvas, podendo tatear toda a planta, sentindo caule, folhas, gavinhas e frutos; degustações guiadas com distintos tipos de vinhos, simultaneamente tendo contato com os tipos de uvas com que são produzidos estes vinhos, para que se possa relacionar o produto à matéria-prima; dentre outras atividades que possam potencializar a utilização dos demais sentidos do visitante com deficiência visual, os quais, em geral, são bastante apurados e podem proporcionar experiências memoráveis.

Estes depoimentos reforçam o que aponta Sassaki (2003), que salienta que as barreiras mais comuns encontradas por pessoas com deficiência nos locais destinados ao lazer e ao turismo são atitudinais e comunicacionais, diretamente relacionadas com a falta de preparo dos funcionários para atender as pessoas com deficiência. Isto é corroborado pelo que afirmam Faria e Motta (2012), destacando sete fatores considerados restritivos para o consumo de serviços turísticos, dentre os quais estão: Tempo, Recursos Financeiros, Questões Pessoais, Importância da Companhia, Barreiras Atitudinais, Barreiras Arquitetônicas e Atendimento.

A seguir, tem-se um gráfico que representa os resultados obtidos com as entrevistas acima descritas e mencionadas, realizadas com pessoas com deficiência visual, demonstrando realmente os fatores de importância para elas durante a visitação em vinícolas, que confirmam o que já foi colocado por Sassaki (2003) e Faria e Motta (2012) a respeito das barreiras encontradas na prática do turismo, sobretudo, quando o turista possui alguma deficiência: 


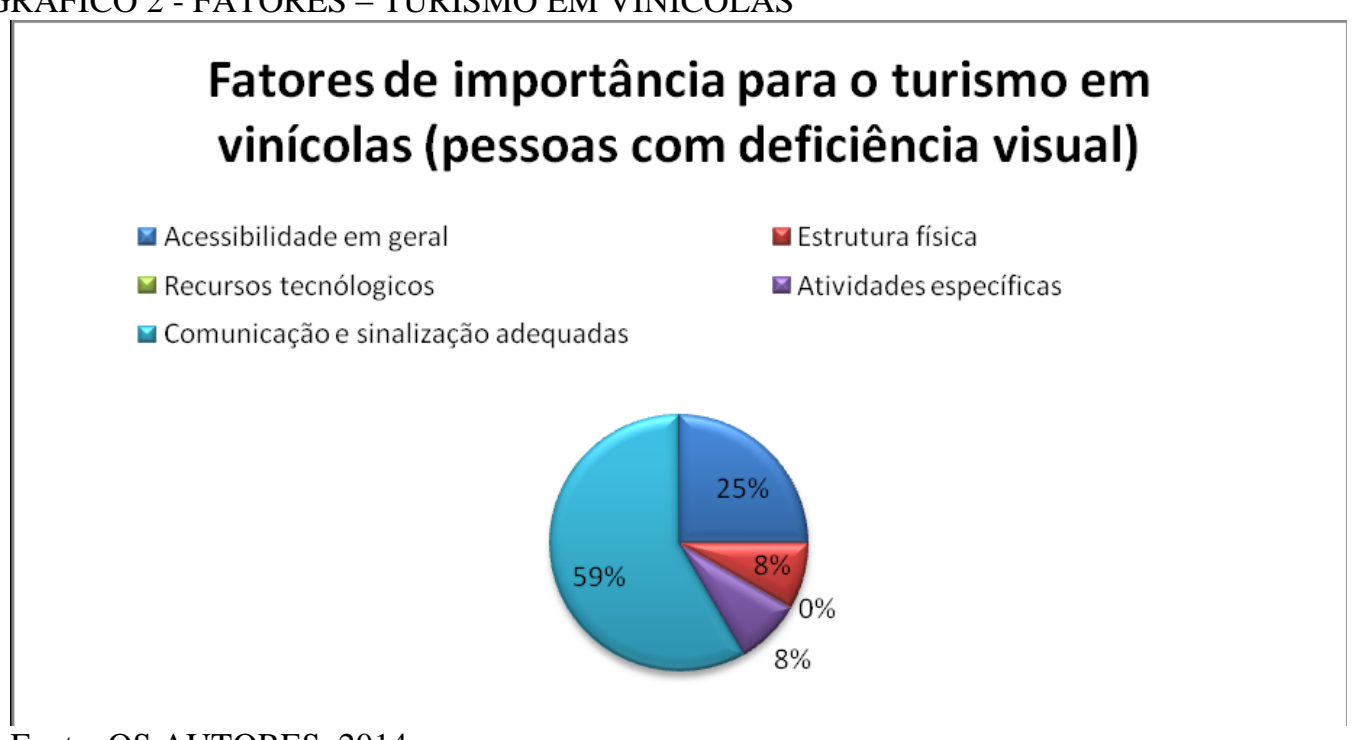

Fonte: OS AUTORES, 2014.

Além dos dados quantitativos abordados, outros de teor qualitativo também foram coletados, principalmente em relação às principais dificuldades encontradas durante a prática de atividades relacionadas ao turismo. Os entrevistados afirmaram que caso quisessem praticar atividades turísticas sozinhos, em sua maioria, não conseguiriam e até mesmo não poderiam, fazendo-se necessária a existência de guias/voluntários para auxiliá-los durante o processo. Salientou-se, ainda, o fato de que a maioria dos locais turísticos ainda não possuíam pisos táteis, sinalização adequada e nem funcionários especializados e que tenham experiência para a realização de um atendimento correto, principalmente ao que concerne à comunicação e sinalização desses locais.

Nesse sentido, retoma-se Bizinelli (2011) que destaca que as barreiras de comunicação e informação são aquelas que têm mais destaque dentre as enfrentadas pelas pessoas com deficiência, o que exige adequações de sistemas, dispositivos e materiais de forma a viabilizar pleno acesso, compreensão e participação na experiência oferecida.

Outra questão abordada foi o interesse dos entrevistados em realizar visitação a vinícolas. Unanimemente os entrevistados afirmaram que havia um interesse em realizar atividades turísticas nesses locais, principalmente, por esses serem capazes de proporcionar uma vivência que se utiliza de seus outros sentidos, permitindo certo conforto e tranquilidade de que, provavelmente, não seriam expostos a situações de tensão e constrangimento por suas limitações. 
Neste contexto, verificaram-se vários comentários relacionados à questão da percepção tátil (e sensorial - paladar e olfato) no desenvolvimento pleno de atividades para pessoas com deficiência visual, aspectos estes que podem ser facilmente explorados no âmbito do enoturismo, desde o plantio/colheita nos vinhedos, como na parte de manipulação das taças para degustação dos produtos. Como salientam Hall e Macionis (1998), o enoturismo pode ser considerado como um sistema centrado na experiência que, de certa maneira, influencia e é influenciado pelos aspectos individuais do visitante e da oferta enoturística como um todo, pois as vinícolas buscam 'entregar' aos seus consumidores uma experiência completa, ao que diz respeito, a vivência dos mesmos na elaboração e degustação dos vinhos.

Em relação aos fatores considerados mais importantes para que a visitação de pessoas com deficiência em vinícolas e vinhedos fosse bem-sucedida, os respondentes indicaram a relevância do atendimento especializado. Outro aspecto tido como relevante foi a estrutura física e a sinalização, já que, havendo uma estrutura adequada, o deficiente visual consegue autonomia na localidade, não ficando dependente de um guia ou acompanhante para construir sua experiência turística.

Em relação aos conhecimentos dos entrevistados sobre enoturismo, ficou claro que eles não possuíam conhecimento sobre este segmento turístico. Contudo, boa parte destes entrevistados já havia realizado alguma atividade relacionada diretamente com a visitação de vinícolas e vinhedos. Sobre a utilização das atividades de enoturismo como uma forma de inclusão das pessoas com deficiência visual, os entrevistados afirmaram que seria relevante e interessante. Alguns comentaram que poderia ser a iniciação do processo de inclusão dessas pessoas no turismo, pois sendo o enoturismo, como já mencionado, uma atividade que possibilita o envolvimento dos sentidos, como paladar, olfato e tato, as pessoas com deficiência visual poderiam ser facilmente participantes de atividades a ele correlatas.

Outro ponto de vista defendido pelos entrevistados é que adaptação de uma propriedade para pessoas com deficiência visual é mais simples do que para o público com dificuldade de locomoção: sinalizações no Sistema Braille, sinalizações sonoras e pisos táteis, juntamente com pessoas capacitadas para o auxílio deste visitante durante a experiência são elementos que já possibilitam uma visitação satisfatória. 
Por fim, os entrevistados salientaram a importância da participação de pessoas familiarizadas com as dificuldades dos deficientes visuais nos processos de planejamento e adaptação de empreendimentos voltados para este público, visando não apenas o cumprimento à legislação estabelecida, mas, também, a criação de facilidades que permitam a vivência plena de uma experiência turística.

\section{CONSIDERAÇÕES FINAIS}

Tendo em vista o que foi abordado no presente estudo, foi possível verificar que havia certa disparidade no discurso da vinícola e dos entrevistados com deficiência visual, os quais afirmaram que em sua totalidade praticavam lazer e turismo e boa parte delas já havia praticado alguma atividade ligada a vinícolas e sua visitação, contrapondo-se a informação de visitação nula de pessoas com deficiência visual na vinícola entrevistada. $\mathrm{O}$ que pode significar uma demanda potencial reprimida, por achar que não receberia atendimento adequado. Fato que se apoia ao pouco 'entusiasmo' dos empreendedores, que não vislumbram tal demanda, deixando de adequar seus estabelecimentos, de treinar seus colaboradores e investir em sinalização e outros itens estruturais, situação que se confirmou com a observação da entrevista do responsável pela vinícola, o qual afirmava ter conhecimentos suficientes sobre a acessibilidade, reconhecer a importância da mesma e, no entanto, ponderava que para a instalação dessa acessibilidade seria necessária uma real visitação desta demanda, provando que este 'investimento' em acessibilidade seria necessário.

Nesta perspectiva, percebeu-se que o responsável pela vinícola reconhecia a necessidade de uma adequação em seu espaço, mas, que esta preocupação era um tanto quanto paradoxal, pois para investimentos mais massivos em estruturas acessíveis, atendimento especializado, entre outros, esperavam por um incremento da demanda que necessitasse das mesmas. Considerando que, essas reestruturações necessárias, na verdade, são asseguradas por lei e deveriam ser preexistentes.

Com isso, verifica-se a importância de um 'diálogo' mais aberto e atento entre o mercado de serviços turísticos e suas possíveis demandas, para que tanto as necessidades de um lado sejam atendidas (lucro, aumento do fluxo turístico), como as 
do outro (boas condições para realização de atividades turísticas e de lazer, atendimento adequado, estruturas específicas e acessíveis, cumprimento das normas de acessibilidade nas instalações, sinalização).

Logo, com a realização deste trabalho espera-se contribuir efetivamente na discussão sobre a acessibilidade e o papel da atividade turística como uma ferramenta para a real democratização do lazer, estimulando, assim novos projetos que abordem essa temática, que ainda é pouco explorada pelos pesquisadores como um todo.

Por fim, sugere-se que pesquisas futuras sejam realizadas para que os estudos acadêmicos referentes às temáticas abordadas sejam aperfeiçoados, como exemplo, pode-se citar: a aplicação de um 'inventário' que analise diretamente a questão da acessibilidade nos empreendimentos vitivinicultores; realização de visitas a esses empreendimentos, utilizando-se como 'sujeitos de pesquisa' as pessoas com deficiência para que essas possam verificar os principais obstáculos encontrados ao realizar uma visita a um estabelecimento, seja ele vinícola ou não. Além disso, sugere-se uma revisitação ao empreendimento mencionado neste estudo, para verificar, na atualidade, como ele está estruturado e se suas instalações permanecem as mesmas, ou se ocorreram adequações.

\section{REFERÊNCIAS}

ABNT - Associação Brasileira de Normas Técnicas. NBR - 9050: Acessibilidade a edificações, mobiliário, espaços e equipamentos urbanos.

ALMEIDA, W. Comunidade surda e o turismo de responsabilidade social: um olhar sobre as diferenças. SEMINÁRIO DE PESQUISA EM TURISMO DO MERCOSUL, Anais... Caxias do Sul, RS, Brasil, 2006.

BAKER, S.; STEPH ENS, D.; HILL, R. How can retailers enhance accessibility: giving consumers with visual impairments a voice in the marketplace. Journal of Retailing and Consumer Services, v. 9, p. 227-239, 2002.

BARBOSA, E. F. Instrumentos de Coleta de Dados em Projetos Educacionais. Publicação do Instituto de Pesquisas e Inovações Educacionais - Educativa, 1998.

BEAMES, G. The rock, the reef and the grape: the challenges of developing wine tourism in regional Australia. Journal of Vacation Marketing, v. 9, n. 3, p. 205-212, 2003. 
BORDAS, E. Hacia el turismo de la sociedad de ensueño: necesidades de mercado, UOC, Barcelona, 2003.

BIZINELLI, C. Enoturismo e Turismo de Experiência: Novas possibilidades para a inclusão de pessoas com deficiência visual. Trabalho de Conclusão do Curso, Curso de Turismo, Universidade Federal do Paraná, Curitiba, 2011.

CAMBOURNE, B.; MACIONIS, N. Meeting the wine-maker: wine tourism product development in an emerging wine region. In: HALL, M.; SHARPLES, L.; CAMBOURNE B.; MACIONIS, N. (Eds.). Wine tourism around the world development, management and markets. Oxford: Elsevier Butterworth-Heinemann, p. 81-114, 2004.

CERVO, A. L. E; BERVIAN, P. A. Metodologia científica: para uso dos estudantes universitários. 3. ed. São Paulo: McGraw-Hill do Brasil, 1983.

CHARTERS, S.; ALI-KNIGHT, J. Who is the Wine Tourist? Tourism Management, v. 23, n. 3, p. 311-319, 2002.

COSTA, E. R. C. Enoturismo: retomando o culto a Baco através do turismo. eGesta Revista Eletrônica de Gestão de Negócios, v. 5, n. 3, p. 27-38, 2009.

DARCY, S. Improving airlines practices by understanding the experiences of people with disabilities, 2009. Disponível em: <http://www.turismoadaptado.com.br /pdf/trabalhos_e_pesquisas/improving_airline_practices_by_understanding_the_experie nces_of_people_with_disabilities.pdf>. Acesso em: 09/03/2014.

DENCKER, A. F. M. Pesquisa em turismo: planejamento, métodos e técnicas, São Paulo: Futura, 1998.

ENOTURISMO BRASIL. A nova geografia do enoturismo brasileiro, 2011. Disponível em: <www.enoturismobrasil.com.br>. Acesso em: 22/01/2014.

FARIA, M. D.; MOTTA, P. C. Pessoas com Deficiência Visual: barreiras para o lazer turístico. Revista Turismo em Análise, v. 23, n. 3, p. 691-717, 2012.

FLOCKER, M. Manual do hedonista: dominando a esquecida arte do prazer. Rio de Janeiro: Rocco, 2007.

GÂNDARA, J. M. G.; GIMENES, M. H. S. G.; MASCARENHAS, R. G. Reflexões sobre o Turismo Gastronômico na perspectiva da sociedade dos sonhos. In: PANOSSO NETTO, A.; ANSARAH, M. G. (Org.). Segmentação do mercado turístico - estudos, produtos e perspectivas. Barueri: Manole, 2009.

GILMORE, J. H.; PINE II, B. J. Differentiating Hospitality Operations via Experiences: Why Selling Services Is Not Enough. Cornell Hotel and Restaurant Administration Quarterly, v. 43, n. 3, p. 87-96, 2002. 
GIMENES, M. H. S. G.; BIZINELLI, C.; MANOSSO, F. C. Enoturismo e Atividades Complementares: Estratégias para a Maximização da Experiência Turística. IX SEMINÁRIO DA ASSOCIAÇÃO NACIONAL PESQUISA E PÓS-GRADUAÇÃO EM TURISMO, Anais... Universidade Anhembi Morumbi, São Paulo, 2012.

HALL, C. M; JOHNSON, G.; CAMBOURNE, B.; MACIONIS, N.; MITCHELL, R.; SHARPLES, L. Wine tourism: an introduction. In: HALL, C. M; SHARPLES, L. CAMBOURNE, B.; MACIONIS, N. (Org.). Wine tourism around the world: development, management and markets. Oxford: Elsevier, p. 1-23, 2004.

HALL, C. E; MACIONIS, N. Wine Tourism in Australia and New Zealand, In: BUTLER, R.; HALL; M.; JENKINS. J. (Eds.). Tourism and recreation in rural areas. Nova Jersey: Wiley, p. 197-224, 1998.

HOGGS, G.; WILSON, E. Does he take sugar? The disabled consumer and identity. Anais British Academy of Management Conference Proceedings. St. Andrews, Scotland, 2004.

IBRAVIN - Instituto Brasileiro do Vinho. Análise Setorial, 2013. Disponível em: <http://www.ibravin.org.br/public/upload/statistics/1380742265.pdf>. Acesso em: 03/05/2014.

IWSR. International Wine and Spirit Research. Disponível em: <http://www.iwsr.co.uk/>. Acesso em: 03/05/2014.

KAUFMAN, C. Shop'til you drop: tales from a physically challenged shopper. Journal of Consumer Marketing, v. 12, n. 3, p. 39-55, 1995.

KUSHANO, E. S; ALMEIDA, W. G. Inclusão social, cidadania e turismo - Uma investigação sobre a existência de serviços adaptados às pessoas com necessidades especiais nos meios de hospedagem da Região Metropolitana de Curitiba. Revista Brasileira de Pesquisa em Turismo, v. 2, n. 4, p. 88-101, 2008.

MARTINS, P. I. S. R. A inclusão pela arte: museus e públicos com deficiência visual. Dissertação (Mestrado em Museologia e Museografia), Faculdade de Belas Artes Universidade de Lisboa, Lisboa, 2008.

MELO, A. M. Acessibilidade: discurso e prática no cotidiano das bibliotecas Acessibilidade e Design Universal. Campinas, SP: UNICAMP/Biblioteca Central Cesar Lattes, 2006. Disponível em: <http://blogs.cultura.gov.br/bibliotecaviva files/2009/05/livro_acessibilidade_bibliotecas.pdf\#page=20>. Acesso em: 08/03/2014.

MINISTÉRIO DO TURISMO. Manual Tour da Experiência 2010: conceituação, 2013. Disponível em:

<http://www.turismo.gov.br/export/sites/default/turismo/o_ministerio/publicacoes/down loads_publicacoes/Estudo_de_Caso_Tour_Experiencia.pdf >. Acesso em: 23/01/2014. 
Turismo acessível: Introdução a uma viagem de inclusão. Volumes I, II e III. Brasília: Ministério do Turismo, 2009.

MITCHELL, R; HALL, C. M; MCINTOSH, A. Wine tourism and consumer behavior. In: In: HALL, C. M; SHARPLES, L. CAMBOURNE, B.; MACIONIS, N. (Org.). Wine tourism around the world: development, management and markets. Oxford: Elsevier, p. 115-135, 2004.

PAGLIUCA, L. M. F.; ARAGÃO, A. E. A.; E ALMEIDA, P. C. Acessibilidade e deficiência física: identificação de barreiras arquitetônicas em áreas internas de hospitais de Sobral, Ceará. Revista da Escola de Enfermagem, USP, v. 41, n. 4, p. 581-588, 2007.

PINE II, B. J.; GILMORE, J. H. The economy experience: Work is theatre \& every business a stage: goods \& services are no longer enough. United States of America: Harvard Business Review Press, 1999.

POPPER, K. A lógica da pesquisa científica. São Paulo: Cultrix, 1974.

SÁ, E. D.; CAMPOS, I. M.; SILVA, M. B. C. Atendimento educacional especializado: deficiência visual. Brasília: SESSP/SEED/MEC, 2007.

SARAIVA, J. Turismo de Experiência oferece Interação. Revista Global Tourism, 2009.

SASSAKI, R. K. Inclusão no lazer e turismo: em busca da qualidade de vida. São Paulo: Áurea, 2003.

SCHMITT, B. Experiential Marketing: How to Get Customers to Sense, Feel, Think, Act, and Relate to Your Company and Brands. New York: Free Press, 1999.

SERRENHO, M.; ÁGUAS, P. O Perfil do Enoturista. Revista da ESGHT-UAIg, n. 15, p. 21-30, 2006.

SILVA, Y. F.; BÓIA, Y. I. K. Turismo e Responsabilidade Social - Uma Reflexão sobre os Direitos das Pessoas com Necessidades Especiais. Turismo - Visão e Ação, v. 5, n. 1, p. 53-65, 2003.

TACH, L. Trends in wine tourism. 15. ago. 2007. Disponível em: $<$ http://www.winebusiness.com/wbm/?go=getArticle\&dataId=50125>. Acesso em: 22/01/2014.

TONIETTO, J. Vinhos brasileiros de $4^{\mathrm{a}}$ geração: o Brasil na era das indicações geográficas. Comunicado Técnico, n. 45. Bento Gonçalves, RS: Embrapa, 2003.

TONIETTO, J. Afinal, o que é terroir? Bom Vivant, Flores da Cunha, v. 8, n. 98, p. 8, abr. 2007. 
TONINI, H. Estado e turismo: políticas públicas e enoturismo no Vale dos Vinhedos. Dissertação (Mestrado em Turismo). Universidade de Caxias do Sul. Caxias do Sul, 2007.

Economia da experiência: o consumo de emoções na Região Uva e Vinho/RS. Revista Brasileira de Pesquisa em Turismo - Rbtur, São Paulo, v. 3, n. 1, p. 90-107, 2009.

UVIBRA. Consumo de vinho per capita - 1998 a 2007. Publicado em 2013.

Disponível em:

<http://www.uvibra.com.br/pdf/Consumo\%20humano\%20individual\%20de\%20vinho\% 20por\%20ano\%20-\%20per\%20capita\%20-\%201998-2007.pdf>. Acesso em: 22/01/2014.

VALDUGA, V. O processo de desenvolvimento do enoturismo no Vale dos Vinhedos. Dissertação (Mestrado em Turismo) - Programa de Pós-Graduação em Turismo, Universidade de Caxias do Sul, Caxias do Sul, 2007.

O Desenvolvimento do Enoturismo no Vale dos Vinhedos (RS/Brasil).

Revista de Cultura e Turismo - CULTUR, ano 6, n. 2, p. 127-143, 2012.

ZANINI, T. V. Enoturismo no Brasil: um estudo comparativo entre as regiões vinícolas do Vale dos Vinhedos (RS) e do Vale do São Francisco (BA/PE). Dissertação (Mestrado em Turismo) - Programa de Pós-Graduação em Turismo, Universidade de Caxias do Sul, Caxias do Sul, 2007.

Recebido em: 15-05-2014.

Aprovado em: 13-06-2014. 